\title{
The Effectiveness of Using Facebook on the Ninth Grade Students' Achievement of English in Jordan
}

\author{
Jebreen A. Hussain ${ }^{1} \&$ Enas N. Al-Ghoul ${ }^{1}$ \\ ${ }^{1}$ School of Education, Hashemite University, Zarqa, Jordan \\ Correspondence: Jebreen A. Hussain, School of Education, Hashemite University, Zarqa, Jordan. E-mail: \\ anasjh@hotmail.com
}

Received: February 21, 2015 Accepted: April 24, 2015 Online Published: August 14, 2015

doi:10.5539/res.v7n11p318 URL: http://dx.doi.org/10.5539/res.v7n11p318

\begin{abstract}
This study aimed at investigating the effectiveness of using Facebook on the English language achievement of the ninth grade students in Jordan. The study was applied in Asia Secondary School for Girls in Amman in the first semester 2014/2015, studying the effect of variables such as teaching method, the cumulative average and the interaction between them. The sample consisted of 68 students divided into two groups. One of them was an experimental group 33 students studied by the Facebook way and the other was control group 35 students studied the same unit in the traditional way. The study used two tools: First: educational material. Second: A comprehensive and reliable test was designed and applied as a pretest to both groups to ensure that they are equal; also they applied the same test after the completion of the study unit. The results showed statistically significant differences between the mean of students in the experimental group studied by the Facebook method and the mean of the control group, in favor of the experimental group. The results also showed statistically significant differences between the mean of students due to the cumulative average. On the other hand, there were significant differences regarding the interaction between the method and the cumulative average. Finally the researchers suggested some recommendations.
\end{abstract}

Keywords: Facebook, cumulative average, English language

\section{Introduction}

Great progress has been achieved so far in information technology and its applications. Such applications have also covered the educational institutions such as schools and universities. Al-Masry (2014) emphasized that he world has witnessed technological progress in education embodied in computer-based learning, hyper media and internet-based learning concepts called the second generation web. This generation depends on several key tools, the most important of which are blogs and social network which can be used effectively in learning. (Al Mahya, 2008).

The internet cyberspace has introduced many social networks such as: My Space, LinkedIn, Friendster and Google plus. However, the most popular and widespread of these are: Facebook, Twitter, and YouTube. (Al-E'nezi, 2013). Facebook occupies the first rank, Google plus occupies the second rank and then followed by YouTube in Jordan (Meqdady 2013). Shaltout (2013) thinks that Facebook is the most effective social network in the educational field, because teachers and students can create groups or pages which enable them to interact and exchange information and ideas, photos, video clips and any educational material.

Many teachers have started using the Facebook to communicate with each other which leads to creating an interactive educational environment for both teachers and students (Juang, 2010). Couillard (2011) stressed the importance of using the Facebook in classrooms today. He also pointed out some negative aspects of using it in education, such as fraud scheme promoters on the web, and unwillingness of some students to use it and negative attitudes of others on the one hand, but he stressed the use of the Facebook in exchanging resources and information between teachers and students on the other hand. Juang (2010) stressed the use of the Facebook in the educational process through its several applications for the teacher and the student as well.

Ibrahim (2013) thought that Facebook could be used in teaching writing English and in communication because it motivates students and helps them overcome many of English learners' errors in writing, sentence phrasing and writing skills. The findings of several studies have emphasized the effectiveness of using Facebook in education. It 
encourages students to learn, keeps them engaged and allows them to communicate with teachers and with each other. It also gives them the opportunity for human interaction and communication in a manner that reflects their mastery of learning skills and increase in their achievements. (Hall et al., 2013; Simpson, 2012; Lam, 2012). Rashad (2011) believed that the use of the social networks motivates students to learn and gives them the opportunity to learn on their own, which will result in improving their achievements.

Omar (2013) stated that some educators believe that Facbook and other social networks have played a key role in dealing with some of the disadvantages of e-learning, such as the human aspects by creating the human impact through the participation and interaction between students and teachers. Despite the great attention and efforts made by the Ministry of Education in Jordan in teaching English and designing the English curriculum, many studies indicated and emphasized that there is a public complaint of the low level of achievement of the English language by students attributed to their negative perspectives of English and their negative attributes towards its importance and the difficulties they face in learning it (Ibrahim, 2013; Khalaf, 2013; Hussein \& AlShdaifat, 2013).

\section{Statement of the Problem}

Many school courses especially English in Jordan are delivered to students in traditional ways which became boring for the students. This reflected on the GPA and the class interaction of the students. Researchers noticed during their field visits to these classes that there is a noticeable weakness in their grades in English. This may have resulted from a system incapable of creating a new generation that copes with the technological and informational revolution. This is why students are bored from using the traditional method of teaching applied by most of the teachers of English which limits the effectiveness and the activity of the students towards learning this subject. This is reflected on their performance and GPA. The Ministry of Education tried to engage the E-learning by using the Edu-Wave program and the Intel program. They emphasized the necessity of using technology, through the actual everyday practice of the teachers inside the classrooms which involves the true adoption of technology in teaching is still weak. Some studies indicated these findings such as: Ibrahim (2013), Wang et al. (2013), Younis and Salehi (2012). So, researchers found the solution by using Facebook in teaching English. The problem of the study tries to find a way to measure the effect of using (Facebook) on the GPA of the elementary ninth grade class in English. This study is an attempt to answer these questions:

- Are there any statistically significant differences at level $(\alpha \leq 0.05)$ in achievement of the ninth grade students in English attributes to the teaching method (Facebook, traditional)?

- Are there any statistically significant differences at level $(\alpha \leq 0.05)$ in achievement of the ninth grade students in English attributes to the GPA (High, Medium, Low)?

- Are there any statistically significant differences at level $(\alpha \leq 0.05)$ in achievement of the ninth grade students in English attributed to the interaction between the method of teaching and the GPA?

\section{Aim of the Study}

This study aims at investigating the effect of using Facebook on the students of the ninth grade in English compared with the traditional method. This study also aims at investigating the effect of GPA of the students and their achievement, and to the interaction between them.

\section{Significance of the Study}

This study gains its significance from the following:

- The great impact, use and widespread of Facebook among people, especially the school children.

- The new trend in education represented in individualized learning and self-learning.

- The researchers conducted on the impact of Facebook and the findings indicated.

- The opportunity Facebook provides for students to improve their English through interaction and communication with teachers and each other.

- Also, this study is one of the first studies that seek to find out the effect of using Facebook in learning English in Jordanian schools.

\section{Limitations of the Study}

- Place Limitations: The study is restricted to Asia secondary school for Girls in Amman, the capital. In the first quarter of the academic

- Year 2015/2015.

- Population limitations: Only the ninth grade students are included in their study. 
- Gender Limitations: Only the male ninth grade students are included in this study.

- The study was confined to unit (The man who wears a Kufiyyeh) from the Action Pack English book for the elementary ninth grade.

\section{Procedural Definitions}

1) Facebook: A social network via the Internet, by which information, pictures, feelings, and ideas are exchanged between people.

2) Facebook Method: Using Facebook in teaching English, to provide the educational material by creating a closed group of students and to display the required assignments, in addition to sharing various types of files such as educational photos, videos, power point, useful links, and announce the important events. Students can see, read, understand, and discuss the assignment among themselves and receive homework. The achievement of their educational goals is checked by means of electronic tests that the teacher posts on Facebook.

3) GPA: The grade achieved by the student at the end of one semester and is measured by gathering the sum of his/her grades during one semester of the same year.

4) The achievement: The sum of all knowledge, information, concepts, and terminology that the student learned in the Unit (The man who wears a Kufiyyeh) measured by the total mark that the student gets in the academic achievement test prepared for this purpose.

\section{Related Studies}

Al-Masry (2014) conducted a study that aimed to investigate the impact of using Facebook on the achievement of the ninth grade students in mathematics in Jordan. The experimental group consisted of 53 students and was taught by using Facebook method. The control group consisted of 51 students and was taught by the traditional method. The results indicated that there was a statistically significant difference attributed to the teaching method in favor of the Facebook method.

Ibrahim (2013) also conducted a study that aimed at investigating the impact of using Facebook in developing writing skills in the subject of English for students in schools in Nablus, Palestine. The sample consisted of 40 students in the primary ninth grade in a private school, and was divided equally into two groups, the first was experimental was taught by using Facebook method. The second was a control group was taught by the traditional method. Results showed mastery of the experimental group which was taught by the Facebook method.

Al-E'nezi (2013) study aimed at investigating the effectiveness of using social networks in the achievement of students in the middle third grade in Medina, Saudi Arabia. The results showed that the most effective social network was Facebook.

Wang et al. (2013) conducted a study aimed at comparing interactive learning environment using Facebook with the traditional learning environment (without Facebook) by university students. The sample consisted of 191 students in advanced English course. 134 students were in the experimental group were taught by using Facebook method, and 57 students were in the control group and were taught by using traditional method. The results indicated a significant positive effect on the scores in favor of the experimental group.

Ekland and Van Doorn (2013) also conducted a study that aimed at investigating the perceptions of students of using chat application available on Facebook and its benefits in learning. The study sample consisted of 20 volunteers from third-year students in the department of psychological studies at Monash University in Australia. The study used a questionnaire of 10 items that included five questions on the Likert scale and four short answers. The results indicated that the students believed that Facebook was a very useful tool for communicating with their lecturer, and that $90 \%$ of them thought that Facebook was an appropriate educational tool.

Omer (2013) conducted a study that aimed at providing a proposed perception to employ the potentials and tools of social networks that can be employed in project-based learning. The proposed perception was applied on a sample consisted of 54 female students from the College of Education at the University of Umm Al-Qura in Makka, Saudi Arabia. The impact of the model on increasing the achievement motivation among students was measured by means of achievement motivation test. The results proved the effectiveness of the proposed perception and its clear impact in increasing motivation for achievement as well as the increase in the positive attitude towards learning through the web. It also showed a positive relationship between the employment of social networks in project -based learning and the increase in achievement motivation and their attitudes towards learning across the web in addition to enhancing the students' abilities in self-learning.

Younis and Salehi (2012) conducted a study that aimed at investigating students' perceptions regarding the use of Facebook in teaching English as a second language. The study sample consisted of 43 students: 26 females and 17 
males from third-year students in the Faculty of Education at the University of Kebangsaan, Malaysia. A questionnaire of 10 items was directed to them. The results indicated that it was possible to use Facebook groups in teaching English as a second language, and that students could learn new vocabulary from reading the comments in the groups, and the auto correct feature that helps in reducing their spelling errors. The study recommended that it was necessary to study the challenges facing Facebook in education, and teachers' suggestions for using Facebook in education.

Petrović et al. (2012) conducted a study aimed at finding out the impact of Facebook on the achievement of Environmental Quality System cycle students at the University of Belgrade in Serbia. The sample consisted of 68 students: 44 females and 24 males from among final year students at the Faculty of Organizational Sciences. A questionnaire was used for data collection. The results showed that Facebook could be used as an educational tool as it increased the productivity of students, led to increasing their environmental knowledge and improve and enhance their achievement levels. The results also indicated that there were no significant differences attributed to gender.

Fewkes and McCabe (2012) studied how Facebook is used by high school students in Ontario, and whether or not using Facebook supports the educational process, through the application of a questionnaire on 63 students from the high school in Ontario. The result showed that $73 \%$ of respondents were using Facebook for educational purposes, and 27\% said that at least one teacher has created ways of using Facebook in teaching. The study recommended that using Facebook in the educational process due to the continuous increase in the popularity of these sites for students.

Simpson (2011) conducted a study that aimed at finding out the degree of Facebook usefulness as an educational tool in English as a Second Language at Seoul University in South Korea. The sample consisted of 121 students of the Conversation subject, who were studying English at the university.The result showed that Facebook is different from other effective teaching tools, and it is an excellent way to keep the boredom away from classrooms, and that a teacher has to use Facebook in teaching.

Juang (2010) also conducted a study aimed at integrating social networks in education. The sample consisted of 88 students specialized in media management at the University of Science and Technology in Taiwan. The sample was divided into two groups: the first was an experimental group (51 students), and the second was a control group 38 students. The study lasted for 16 weeks. A pre-post test was applied to measure the achievement and a questionnaire to study the degree of correspondence between educational models and the interview to provide qualitative evidence to explain the quantitative data. The results showed a statistically significant difference in achievement for the experimental group. They also showed that learning based on the use of Facebook is better than learning in the classroom model, and the use of Facebook as a tool in education increases motivation towards learning.

Selby (2009) conducted a study aimed at finding out whether Facebook had a role in teaching a unit of Earth Sciences. The study sample consisted of 78 students in this unit, in Durham University. The study lasted for a period of 12 weeks and used the survey method. 60 Students joined in the experimental group. $80 \%$ of whom participated in the published material and $78 \%$ of the sample had used Facebook for revision before the exam to take advantage of videos that summarize the material. The results indicated that the use of Facebook in teaching was very useful. It also indicated that the students felt comfortable when sharing their ideas and commenting on them from their peers, Facebook can also be used as an effective tool for education with the possibility to use it with difficult topics including those they are interested in outside the classroom. Facebook can be used to support education with videos and links, this leads to excitement and reduces confusion.

Al-Otaibi (2008) conducted a study aimedat recognizing the impact of Facebook on the Saudi university students. He found that the prevalence of using Facebook among Saudi university male and female students was $77 \%$. A main factor of using it was the role of parents and friends and their influence on recognizing it, which motivated them to spend much time using Facebook. This factor came in the first place in use. The study concluded that Facebook has achieved what other media have not achieved and the use of Facebook has had a more effective impact on personality than most of other media.

Through reviewing previous studies on our subject, most studies indicated that there is a marked superiority of (Facebook) over the traditional method. The previous studies showed the importance of the teaching process and its effects on the achievement of learning certain skills. The previous studies can be summed up as follows:

Studies showed statistically significant differences of the method of learning in favor of (Facebook) like: Al-Masry (2014), Al-Otaibi, (2008), Ibrahim (2013), Ekland and VanDoorn (2013), Wang et al. (2013), Omar (2013), Al-E'nezi (2013), Petrović et al. (2012), Younis and Salehi (2012), Simpson (2011), Juang (2010), Selby (2009). 
One study showed that Facebook was not different from other technological methods. Simpson (2011).

Most of the previous studies showed advance in the groups that learned using (Facebook) on the traditional methods.

Most of the previous studies that dealt with (Facebook) in different topics and various academic stages. They indicate that Facebook is more effective in most topics and courses in various academic stages.

Some studies have focused on university stage: Omar (2013), Wang et al. (2013), Petrović, et al. (2012) Younis and Salehi (2012), Simpson (2011), Juang (2010), Selby (2009), Al-Otaibi, (2008), some of the study dealt with the primary and secondary stages: Al-Masry (2014), Al-E'nezi (2013), Wang et al. (2013), Ibrahim (2013), and was similar to some of the previous studies that studied Facebook and English and ninth grade students.

This study focused on the effectiveness of (Facebook) and GPA and the interaction between them. The study benefited from the previous studies in putting goals, questions of the study, the development of educational material and in designing the theoretical framework of the study.

This study differs from previous studies in that it focuses on the elementary stage and focuses on the English language which most students find it difficult. The researchers used the results of the previous studies in interpreting this study and developing the instrument of the study.

\section{Method and Procedures}

\subsection{Study Methodology}

The experimental method was used by comparing the experimental group achievement, which used Facebook with the control group which the traditional method and the impact of the GPA on achievement.

\subsection{Study Sample}

The study sample consists of 68 ninth grade students in Asia Secondary School/Amman, in the first semester 2014/2015. The groups and the school were intentionally chosen due to the availability of resources, tools and equipment and facility needed for the study. The sample groups were intentionally chosen and divided into 2 groups: the first group is experimental with 33 students. The experimental group was taught by Facebook method. The second group is a control one with 35 students from ninth grade. This group was taught the same unit from English book by the traditional method.

Table 1 shows the distribution of the groups according to the variables.

Table 1. The study sample distribution according to the variables and levels

\begin{tabular}{llllll}
\hline Variable & \multicolumn{2}{l}{ Teaching method } & GPA & \\
\hline Level & Facebook & Traditional & High & Medium & Low \\
Number & 33 & 35 & 38 & 17 & 13 \\
Percentage & $48.5 \%$ & $51.5 \%$ & $55.9 \%$ & $25 \%$ & $19.1 \%$ \\
\hline
\end{tabular}

\subsection{Study Instruments}

\subsubsection{Educational Material Designed, according to the Facebook Method}

The unit "The man who wears a Kufiyyeh" was selected from the ninth grade syllabus of English as it is relevant to the study objectives, methodology and proposed educational activities. The behavioral objectives were prepared and written, in addition to preparing a material appropriate for the use of Facebook in teaching. The material included, learning objectives, content teaching strategies was developed to make it to learning sources, teaching aids and evaluation. Four teaching plans were done. The teaching material was also adapted making it suitable for the proposed learning activities for the Facebook method, along with compliance with the text content, where learning activities were prepared to teach the unit using the Facebook method and included educational videos extracted from YouTube site, images, written texts, worksheets being of effective role in enrichment of learning and Power Point. Moreover, several presentations were prepared to present the material in an exciting and interesting manner. Electronic games were also designed in a manner suitable for the content of learning Unit. All of the aforementioned were designed in a way that brings enjoyment, suspense and fun. They were posted on Facebook to suit the material described as follows:

- It was designed in a way that suits students at different levels and their growth features. 
- The learning material contains multimedia that mixes preparing learning activities: video clips, electronic games, power point slides, pictures with sound effects, electronic texts in sites related to the same subject of the unit, and presented in exciting and interesting way. All materials were designed to give pleasure, thrill and fun to the students and was posted on the Facebook page to fit the content. The student can move from one part to another at his/her well and at her personal speed, and then she gets electronic test that shows her how much she comprehended from the subject. It also enables her to evaluate herself and discover her level, and she also can determine the mistakes that faced her to avoid them in the future. The material designed on Facebook enables the student to go back and see the learning subject which was taught the class to study it again and again according to her personal capacity of totally comprehend for the subject.

- The material was designed to enhance the student role and provide instant feedback for them in order to achieve the desired learning outcomes.

The Facebook method has been developed in teaching based on the following steps:

1) The teacher creates an account and a closed group on Facebook for the ninth-grade students, then invites them to join as members of this group. The students have already made personal accounts on Facebook. All of the study members own computers at home.

2) The teacher downloads the tasks that she wants on Facebook one day prior to the actual teaching date. The students see the task, try to understand and discuss it between each other.

3) The teacher discusses students about the task and ensures the achievement of the task objectives; this can be done through electronic tests that the teacher has posted on the site to obtain a direct feedback on their performance level.

4) The teacher downloads files of videos, photos, texts and power point slides, in addition to worksheets and activities that the teacher will use to illustrate the ideas and lessons on Facebook, so that any student can go back to lessons any time she wants.

5) Designing Electronic educational games and sharing them on the Facebook site for students to download on their computers and play these educational games. This enhances the learning material and create a learning atmosphere of fun and thrill.

6) Receiving and sending homework through Facebook, and informing students with important announcements via Facebook.

7) Assigning students to search for files related to the subject on the Internet, and to share them with their colleagues on Facebook.

\subsubsection{Validity and Reliability of the Educational Material}

The learning material was validated after preparing it in its initial form, by consulting 10 specialists with $\mathrm{PhD}$ and MD, specialized in educational technology, English curriculum and IT. The consultants were from Alhashmeya, Jordan, Yarmouk Universities, and specialists in the Ministry of Education. They were asked to give their opinion about the clarity of the learning material, accuracy, sequence, appropriate use of sound and color, and the sufficiency of the learning content. Based on their opinions, the material was modified till it reached to its final form. The reliability of the material was tested by applying it to outside the study group consisted of 25 students from ninth grade class for 2 weeks. Appropriate modifications were made based on students' opinions and according to the researchers' notes during the outside sample application. This helped researchers to determine the time needed to apply the material on the original sample for 2 weeks.

\subsubsection{Achievement Test}

The test was prepared to measure the achievement of the elementary ninth grade students in the English language course in the unit ("The man who wears a Kufiyyeh!"). After analyzing the unit content which included concepts, skills and questions. Then, all of these were put in a specification table. The test consisted of 25 questions type MCQ. Each question has 4 answers one of them is correct. Each question has two point if the answer is correct and 0 score if the answer is wrong, so the full mark is 50 and the lowest mark is 0 , Coefficients have been calculated the difficulties for the test which ranged between $0.25 \%-0.78 \%$, while discrimination coefficients ranged between $0.20-0.39$.

\subsubsection{Test Building Steps}

The researchers analyze the unit content (in English course) and build specifications table for the unit then based on it the achievement test was built. 
A draft of the test was made, consisting of 25 paragraphs in the form of MCQ each has one a correct answer out of 4 choices.

Consulting the credibility of a group of judges to make sure that:

The test paragraphs are clear and correct scientifically.

The accuracy of the linguistic phases of the tests.

The suitability of the test paragraphs for the ninth grade students.

The test paragraphs contained the learning objectives of the unit.

\subsubsection{The Test Validity and Reliability}

To confirm the validity of the test and to make sure that the content of the test is suitable to the knowledge levels contained in the content analysis, and how test questions represent the goals and covers the content of the unit, to confirm this a judge committee consisted of $10 \mathrm{PhD}$ and $\mathrm{MD}$ specialized in educational technology, English curriculum, evaluation and measurement, the consultants were from Alhashmeya, Jordan, Yarmouk Universities, and specialists in the Ministry of Education. The committees were asked to give opinion on how the test questions are appropriate in terms of phrasing, comprehensiveness of the questions for the content of the unit. Some tables were modified and rephrased based on their suggestions and the test was formed in its final shape as 25 paragraph as MCQ, and Appendix 1 show the test in its final shape, and to calculate the validity of the test, Cronbach Alpha internal consistency coefficient, was used which was 0.82 , which is an appropriate value can be relied upon for purposes of scientific research (Odeh, 2004).

\subsection{The Study Procedures}

The researchers received an approval letter from the First Directorate of Education in Amman based on a recommendation letter issued by Hashmite University.

The study instruments were prepared which include: the educational material prepared to fit the Facebook method, the pre and past tabs.

(Validity and reliability of the instruments were previously confirmed).

The experimental and control samples were randomly chosen. The pretest was given, and the results were registered.

A closed group of the ninth grade students was created for the experimental group.

The experimental and control groups were taught by the same teacher.

Teaching of the two groups lasted for three weeks (15 lesson periods).

The researchers kept in touch with the teacher by using the Facebook for guidance and supervision purposes.

After the application of the two groups, the test was given and the data were calculated and were obtained by using the SPSS program.

\subsection{Variables}

8.5.1 Independent Variables

1) Teaching Method with 2 levels:

Facebook method.

Teaching using Traditional method.

2) GPA which has 3 levels:

The student scores in semester 80-100 high.

The student scores in semester 67-79 medium.

The student scores in semester 50-66 law.

\subsubsection{The Dependent Variable}

The scores the students achieved by sitting for the test on the unit ("The man who wears a Kufiyyeh").

\subsection{Statistical Procedure}

The results were analyzed using (SPSS) and the mean grades were calculated, standard deviations, T-test, and Two-Way ANOVA,the effect of learning method, the GPA and the interaction between them. 


\subsection{The Study Design}

The study is a quasi-experimental one. The experimental and control groups were selected for as follows:

$\mathrm{O} \times \mathrm{O}$

$\mathrm{O}-\mathrm{O}$

$\mathrm{O}$-The pretest and the post test of the groups

$\mathrm{X}$-: Treatment (Facebook Method)

- The traditional method.

\section{Results}

\subsection{Results Related to the Equivalence of the Study Groups}

A test was performed for both groups (the experimental group and the control group) to confirm the equivalence of both groups when the mean of grades were calculated and the standard deviation for both groups. Table 2 shows the results:

Table 2. Means, Std. Dev. for the performance of the 2 groups on the pre-test relating to the Teaching method

\begin{tabular}{lccc}
\hline $\begin{array}{l}\text { Teaching } \\
\text { method }\end{array}$ & Number & Mean & Std.Deviation \\
\hline $\begin{array}{l}\text { Facebook } \\
\text { method }\end{array}$ & 33 & 8.272 & 4.177 \\
$\begin{array}{l}\text { Traditional } \\
\text { method }\end{array}$ & 35 & 7.914 & 3.928 \\
\hline
\end{tabular}

Table 2 indicates that there are clear differences between the means of both study groups. The mean of the Facebook method is 8.27 and the mean of the Traditional method is 7.91. To discover the difference between these means, $\mathrm{T}$ test is used for both groups on the pre-test. Table 3 shows the results.

Table 3. The result of $\mathrm{T}$ test for the performance of the 2 groups in the equivalence pre-test according to the teaching method

\begin{tabular}{lclll}
\hline $\begin{array}{l}\text { Teaching } \\
\text { method }\end{array}$ & Mean & $\begin{array}{l}\text { Std. } \\
\text { Deviation }\end{array}$ & F & Sig \\
\hline $\begin{array}{l}\text { Facebook } \\
\text { method }\end{array}$ & 8.272 & 3.928 & .358 & .717 \\
$\begin{array}{l}\text { Traditional } \\
\text { method }\end{array}$ & 7.914 & 4.177 & & \\
\hline
\end{tabular}

Table 3 shows that there is no statistical significance at the level $(\alpha \leq 0.05)$ due to the method of teaching of the students pre achievement of English, T. value (0.358), and the significance level (.717). These primary results indicate the equivalence of the 2 groups.

\subsection{Results Related to Study Questions}

\subsubsection{First Question}

Are there any statistically significant differences at level $(\alpha \leq 0.05)$ in achievement of the ninth grade students in English attributes to the teaching method (Facebook, traditional)?

To answer the question, the means and the Std. Deviation were calculated for the sample on the post test. Table 4 shows the results. 
Table 4. Means and Std.Dev. of the study sample performance on post- test according to the teaching method

\begin{tabular}{llll}
\hline Teaching method & Frequency & Mean & Std.Dev. \\
\hline Facebook method & 33 & 11.97 & 2.069 \\
Traditional method & 35 & 9.57 & 3.432 \\
Total & 68 & 10.74 & 3.079 \\
\hline
\end{tabular}

The results indicate that Facebook method has a mean of 11.97 with 2.069 SD in the post-test, while the Traditional method group got a mean 9.57 with $3.432 \mathrm{SD}$ in the post-test. To identify the statistically significance of these differences between the means, the (Two-Way ANOVA) test was used; table 5 shows the results.

Table 5. Two-Way ANOVA of the effect of teaching method and the student GPA and the interaction between them

\begin{tabular}{lllllll}
\hline Source & $\begin{array}{l}\text { Total } \\
\text { square }\end{array}$ & DF & $\begin{array}{l}\text { Square } \\
\text { means }\end{array}$ & F & Sig & $\begin{array}{l}\text { square ETA } \\
\text { (effect size) }\end{array}$ \\
\hline Method & 153.241 & 1.00 & 153.241 & 66.106 & $* 0.000$ & 0.15 \\
GPA & 370.808 & 2.00 & 185.404 & 79.980 & $* 0.000$ & 0.13 \\
Method and & 22.203 & 2.00 & 11.101 & 4.789 & $* 0.012$ & 0.06 \\
$\begin{array}{l}\text { GPA } \\
\text { interaction }\end{array}$ & & & & & & \\
Error & 143.724 & 62.00 & 2.318 & & & \\
Total & 635.235 & 63.00 & & & & \\
\hline
\end{tabular}

*with statistically significance at level $(\alpha \leq 0.05)$.

Table 5 shows that there are statistically significant differences at significance level $(\alpha \leq 0.05)$ in the post-test due to the method of teaching because Eta square is 0.15 , which shows the effect size used to determine whether there is a difference between the means, the Eta square shows a large effect size. This means that the experimental group students achievement means exceed the achievement means of the control group students because the effect size is large at 0.14 or above, medium at 0.06 , and low at 0.01 , Nasar (2006).

\subsubsection{Second Question}

Are there any statistically significant differences at level $(\alpha \leq 0.05)$ in achievement of the ninth grade students in English attributes to the GPA (High, Medium, Low)?

To answer this question the means and the SD were calculated for the answers of the study sample in the post-test and table 6 shows the results.

Table 6. The means and the SD were calculated for the performance of the study sample in the post test according to the GPA variable

\begin{tabular}{llll}
\hline Average & No. & $\begin{array}{l}\text { Post test } \\
\text { Mean }\end{array}$ & Std.Deviation \\
\hline High & 30 & 12.66 & 2.00 \\
Medium & 23 & 9.00 & 2.17 \\
Low & 15 & 7.38 & 2.46 \\
Total & 68 & 10.74 & 3.07 \\
\hline
\end{tabular}


The results of table 6 indicate that the group with GPA (High) got the highest mean in the post-test 12.66 with SD 2.00 , and the group with GPA (Medium) got the second rank with a mean of 9.00 and SD 2.17, finally the group GPA (Low) with a mean of 7.38 and SD 3.07.

From table 5, the result shows that there are statistically significant differences at significance level $(\alpha \leq 0.05)$ in the post-test due to the GPA, the (F) value 79.98 with significant level $(0.000)$ which is less than $(\alpha \leq 0.05)$. To know the statistically significance of these differences between the means, the (Two-Way ANOVA) test was used (Table 5). Scheffe test for post comparison was used and table 7 shows the result.

Table 7. The result of the post-compression between the means of the post-test for the achievement of the ninth grade students in English

\begin{tabular}{llll}
\hline GPA (Mean) & High (12.66) & Medium (9.00) & Low (7.38) \\
\hline High (12.66) & $*$ & $*$ \\
Medium (9.00) & & & $*$ \\
Low (7.38) & & \\
\hline
\end{tabular}

Table 7 shows that difference in the mean of the GPA variable has statistically significance at a level $(\alpha \leq 0.05)$.

GPA (High) in comparison with (Medium) (Low): All the differences were in favor of the High GPA with a mean of 12.66 compared with (Medium) which has a mean of 9.00 with a difference of 4.97 and (Low) which has a mean of 7.38, an (High), i.e. the achievement of the student with High GPA in English is better in achievement than the groups GPA: Medium, and Low.

GPA (Medium) in comparison with GPA (Low): All the differences were in favor of GPA (Medium) with a mean of 9.00 compared to GPA (Low) with a mean 7.38 i.e. the achievement of the student with a GPA (Medium) in English was better than the achievement of the students with GPA (Low).

Table 5 from the Two-Way ANOVA analysis shows that there are statistically significant differences between the means of the student in the post-test due to the GPA, as the (F) value 79.98 with the significance difference $(0.000)$. And to know places where there are differences between the GPA levels, (Scheffe) test was used for post comparisons and table 7 shows the results.

\subsubsection{Third Question}

Are there any statistically significant differences at level $(\alpha \leq 0.05)$ in achievement of the ninth grade students in English attributed to the interaction between the method of teaching and the GPA?

Referring to table 5 , the result shows that there are statistically significant differences at a $\leq 0.05$ due to the effect of interaction between the method of teaching and the GPA in the achievement of an elementary ninth grade students in English where F value was 4.78, with significance level 0.012.

\section{Discussion and Recommendation}

\subsection{Discussing the Results Related to the First Question}

Are there any statistically significant differences at level $(\alpha \leq 0.05)$ in achievement of the ninth grade students in English attributes to the teaching method (Facebook, traditional)? The results indicated that the Facebook method is more effective compared to the traditional method. This result is achieved because of the following:

The effectiveness of Facebook method because it is a feature of the electronic method, so it helps to get rid of the negative sides of the traditional teaching that depends on simple instructing.

Students in the experimental group benefited from the Facebook method, which was based on learning by doing, where they were offered material which used integrated written texts with video clips , still pictures, PowerPoint slides, electronic games, electronic tests, and links to web sites directly related to the subject material. All of these make the students accept them actively and make them interactive participants in the classroom and with the teacher. They also help students master the skills, concepts and grammar and increase their motivation toward learning. It seems that education built on reinforced techniques of modern technology showed statistically significant differences, as opposed to the control group that received the material in a traditional way and without any techniques, students are accustomed to see in the all lectures. 
The result of this study may be related to the fact that using Facebook in teaching produced a new method different from the traditional methods that the students have got used to in English lessons where this way give chances for the student to explore what she will learn through providing her with a list of the expected outcome after the lesson. This differs from what the student used to have in the traditional method. So this change in the method of teaching led to more active students and encourage them to study English more.

It seems that this method pay attention for the individual differences among students. Student learns from the files according to their abilities and aptitudes because they have the learning material and the unit on their Facebook page, so they can be replicated and found it at any time and whenever they want, away from the embarrassments of normal classroom situation.

The reason for this result may be due to the proactive role of the Facebook in strengthening social interaction and communication between students themselves and their teacher as well, which has increased both their love for the material and tendency for a continuous follow- up. It also provided them with opportunities for communication and discussion among themselves and with their teacher in much greater degree than what is happening in a classroom using the traditional method.

The results of this study agree with each of the following study: Al-Masry (2014), Al-Otaibi, (2008), Ibrahim (2013), Ekland and VanDoorn (2013), Wang et al. (2013), Omar (2013), Al-E’nezi (2013), Petrović et al. (2012), Younis and Salehi (2012), Simpson (2011), Juang (2010), and Selby (2009). The consensus is on the existence of a positive impact of using Facebook in student achievement. All these studies confirmed the efficiency of Facebook in increasing the achievement of the students in all subjects. They disagree with Simpson (2011) who said that Facebook method did not petter than the other technological methods in the achievement of the student.

\subsection{The Discussion of the Results Related to the Second Question}

Are there any statistically significant differences at level $(\alpha \leq 0.05)$ in achievement of the ninth grade students in English attributed to the interaction between the method of teaching and the GPA?

The results indicated that there are statistically significant difference at $a \leq 0.05$ in the achievement of the ninth grade student in English. These results may be due to the fact that the students who got higher sores than others who have more tendency to study the unit using Facebook method that contain a variety of stimulants due to their higher academic rank and their tendency to learn more than the lower grade students .

The student's higher score has more motivation to learn which is reflected on her/his academic achievement, and her/his interaction inside the class and the individual differences between the students make their achievement different lately.

The reason may be that the Facebook method which contains videos, software, activities, homework, electronic tests, direct feedback, communication with the teacher and peers, these materials contain more information about the unit which enabled the students to earn more information bigger than what is in the unit and enriching their knowledge about the subject that they learn thereby improved their achievement, in contrast to the control group that studied the subject in the school book only, and made the student with GPA (High) trend to learn in this way and increases their motivation and activity in English and became better in achievement than the groups GPA: (Medium, and Low). This is also applied to the students with a GPA (Medium) each is their achievement according to their ability in English was better than the achievement of the students with GPA (Low).

\subsection{Discussing the Results Related to the Question 3}

Are there any statistically significant differences at level $(\alpha \leq 0.05)$ in achievement of the ninth grade students in English attributed to the interaction between the method of teaching and the GPA?

The results indicated that there were statistically significant differences at $(\alpha \leq 0.05)$ in the effect of the interaction between the teaching method and the GPA in the achievement of the ninth grade students in English, this result may be related to the none equality of all the students in the available opportunities which was provided by the school and they also were not under the same circumstances that go along with the study,

This result may be attributed to using the Facebook method that affected the students in general, and those with GPA (High) in particular, where the results were in favor of the Facebook method, thus confirmed the effect of the interaction. There were significant differences in favor of interaction between the Facebook method and GPA which is larger than the interaction between the traditional method and GPA of the students. Perhaps this result may be attributed to students' tendency to use E-Learning patterns such as the Facebook method, and the differences in interacting ability and communication with this type of students on the one hand, thee activities, homework, games, electronic tests and communication between students and with the teacher, on the other hand 
they are presented in a way that increased their English learning concepts, skills and rules. This generated statistically significant interaction with GPA (High and Medium) students between the method and GPA, and made the student GPA an active factor in the interaction between the method and GPA. It is a natural result that students with lower GPA tend less to learn using modern technology than their high and medium GPA counterparts.

\section{Recommendations}

In light of the previous findings researchers recommend the following:

Using Facebook in the elementary education to help the student using e-learning.

Designing software based on Facebook compliable with the students psychological and mental frames in different fields and different methods.

Drawing the attention of English curriculum authors for the need of using Facebook to benefit from its properties in enriching the curriculum with modern sophisticated techniques.

Holding training courses for teachers to benefit from Facebook services, potential in education and to develop their teaching skills and keep up with technological developments

Drawing attention to students with GPA (low and medium) to raise their academic and technological abilities and benefit from Facebook potential in education.

Conducting similar studies to reveal the effectiveness of the using of Facebook in teaching English language in other school stages by dealing with other variables.

Conducting further studies about the effect of using Facebook in teaching English for the entire curriculum for the elementary stage.

\section{References}

Abu Shanab, H. (2013). Social Networking Techniques. Uses and Advantages. Action Pack 9. The Ministry of Education, Jordan.

Al Mahya, A. (2008). The Impact of Using Second-Generation E-Learning on Cooperative Learning Skills of Teachers -College Students in Abha. PhD Thesis Umm AlQura University, Saudi Arabia.

Al-E'nezi, J. (2013). The Effectiveness of Using Social Networks in the Achievement of Science and the Trend towards Knowledge Society with the Middle Third-grade Students in the city of Medina. PhD Thesis, Umm Al Qura University, KSA.

Alexa. (2014). http//www.alexa.com

Al-Masry, A. (2014). The Impact of using Facebook in the Achievement of Elementary Ninth-Grade Students in Mathematics. Master Thesis, Hashemite University, Zarqa, Jordan.

Al-Otaibi, J. (2008). Effect of Facebook on Saudi University Students. Master Thesis, King Saud University, Riyadh, KSA.

Couillard, C. (2011). Facebook: The Pros and Cons of Use in Education. A research paper submitted in partial fulfillment of the requirements for the Master of Science Degree, University of Wisconsin-Stout.

Ekland, A., \& Van Doorn, G. (2013). Face to Facebook: Social Media and the Learning and Teaching Potential of Symmetrical, Synchronous Communication. Journal of University Teaching and Learning Practice, 10(1), 6. Retrieved February 1, 2015, from http://www.alukah.net/Spotlight/0/59302/\#ixzz2jhBfa72D

Fewkes, M., \& McCabe, M. (2012). Facebook: Learning Tool or Distraction? Journal of Digital Learning in Teacher Education, 28(3) 92-98. http://dx.doi.org/10.1080/21532974.2012.10784686

Hall, M., Hanna, L., \& Huey, G., (2013). Use and Views on Social Networking Sites of Pharmacy Students in the United Kingdom. American Pharmaceutical, 77(1), 234-242. http://dx.doi.org/10.5688/ajpe7719

Hussain, J., \& Alshdaifat, W. (2013). The Effectiveness of Using Blended Learning on the Academic Achievement of Seventh Grade English Students in Jordan. EJSS, 38.

Ibrahim, M. (2013). Effect of Using Facebook in Improving Students' Writing Skills in English for Primary Ninth Grade. Master Thesis, Al-Najah National University, Nablus, Palestine.

Juang, Y. (2010). Integrating Social Networking Site into Teaching and Learning (pp. 240-251). Proceedings of the 18th International Conference on Computers in Education. Asia-Pacific Society for Computers in Education Putrajaya, Malaysia. 
Khalaf, D. I. (2013). The Impact of Using of Interactive Whiteboard in the Achievement of English for Eighth-grade Students in Jordan. Master Thesis, Hashemite University, Zarqa, Jordan.

Khalaf, A. (2004). Measurement and Evaluation in the Instructional Process (1st ed.). Al-Amal House for publication and distribution, Irbid, Jordan.

Lam, L. (2102). An Innovative Research on the Usage of Facebook in the Higher Education Context of Hong Kong. The Electronic Journal of E-Learning, 10(4), 377-683.

Meqdady, K. (2013). Social Networks Revolution (1st ed.). Dar Al-Nafaes House, Amman, Jordan.

Ministry of Communications and Information Technology. (2012). Survey on the use of Information \& Communication Technology in Jordanian schools. Amman, Jordan.

Nassar, Y. (2006). The Use of the Effect Size to Examine the Practical Significance of the Results in Quantitative Studies. Journal of Educational and Psychological Sciences, 7, 36-59.

Omar, A. (2013). A Proposed Conception in Employing Social Networking in Project -Based Learning and its Impact on Increasing Achievement and Motivation and their Attitudes Towards Learning Through the Web. Third International Conference on E-learning and Remote learning, Riyadh.

Petrovic, N., Petrovic, D., Jeremic, V., Milenkovic, N., \& Cirovic, M. (2012). Possible Educational Use of Facebook in Higher Environmental Education. ICICTE Proceedings, University of Belgrade, Serbia.

Qubaisi, A., W. (2007). Measurement and Evaluation: Renovations and Discussions (1st ed.). Jareer House for Publishing and Distribution, Amman, Jordan.

Rashad, F. (2011). The positive Return of E-learning. E-learning Magazine, V, 4-5. Retrieved from http://emag.mans.edu.eg/index.php?page=news\&task=show\&id=321

Selby, D. (2009). Facebook: An Educational Support Tool for Teaching Earth Science. Department of Earth Sciences, Durham University, 3(22), 56- 60. http://dx.doi.org/10.11120/plan.2009.00220056

Shaltout, M. (2013). Facebookas a Learning Management System. E-learning Magazine. Retrieve from http://emag.mans.edu.eg/index.php?page=news\&task=show\&id=321 retreivd at 5/1/2015

Simpson, M. (2011). ESL @ Facebook: A teacher's dairy on using Facebook. Teaching English with Technology, 12(3), 36-48.

Wang, J., Chun-Fu, C., Lin, W., \& Emily, W. (2013). Meaningful Engagement in Facebook Learning Environments: Merging Social \& Academic lives. Turkish On line Journal of Distance Education, 14(1), 26.

Younis, M., \& Salehi, H. (2012). The Effectiveness of Facebook Groups on Teaching and Improving Writing: Students' Perceptions. International Journal of Education and Information Technologies, 6(1) 87-96.

\section{Appendix A}

The test in its final shape.

\section{1-Khalid's conduct at work is exemplary because:}

a-he follows the code of the workplace ethics.

b-he doesn't work hard

c-he abides by the company's dress code.

d- $(a+c)$

\section{2-"Khalid behaves very properly in the office". One aspect of his behavior is that:}

a-He doesn't respect the company's dress code.

b- He accepts bribe.

c- He has a positive attitude.

d- He cheats.

\section{3-What is the punishment of the employee who doesn't respect the company's dress code?}

a-He is sent home to change the clothes. b- He receives a verbal warning.

$\mathrm{c}-(\mathrm{a}+\mathrm{b})$

d- none of them

\section{4-The word from the text that means (set of laws rules according to which people behave):}

a-conduct b-ethics c-abide by d-code 
5-The underlined pronoun $(I)$ in the first paragraph refers to:
a- Saleh Musa
b-Khalid
c-any employee
d-colleagues

6-The judge refused the and sent the thief to jail.

a-code b-bribe c-efficiently d-tunic

7- Choose the suitable item to complete the mini dialogue:

Khaled: What should I wear for the job interview tomorrow?

Saleh: You have to wear --------------- clothes to leave a good impression..

a-casual b- bright c-formal d-fashionable

8-You can wear fashionable clothes for-

a- football match b-a business meeting c-school d-a friend's birthday party

9-The black colour is typically associated with

a-excitement b-happiness c-sadness d-emotions

10-My grandpa wears the Jordanian national costume. The underlined word (costume) means:

a-The traditional outfit it of a particular culture.

b-An item of clothing worn on, and covering the head.

c-Part of the garment that covers the arm.

d-An item of clothing made of wool and covering the upper part of the body.

11-Sari is the traditional garment in India. The underlined word (garment) means:

a- piece of furniture. B- A style of clothing. C- A piece of clothing. D- A type of food.

12- The speaker describes this clothing item:

a-This is my bright jumper.

b- Can you borrow me your striped T-shirt?

c-I like smart clothes.

d-I wear fashionable clothes for parties.

13-Which of the following sentences is correct?

a-The blue whale is the most heavy animal in the world.

b- Oxygen is the cheaper natural resource.

c- I live in the comforablest city in the world.

d-The Lut Desert in Iran is the hottest place in the world as of 2005.

14-Which one of the following sentences includes a mistake?

a-Some children are louder than others.

b- Mt. Everest is higher than Mt Fuji.

c-A desert is drier than a jungle.

d-A blue whale is the heavier animal in the world.

15-This is the football match I've ever watched. It is even match.

a-good/more exciting b-better/more exciting c-best/more exciting d-best/most exciting

16- A: Can I wear this shirt for a business meeting? B: Shirts aren't suits for a business meeting.

a-so formal as b-as formal as $\quad \mathrm{c}$ - more formal as $\quad \mathrm{d}$-as formal than

17- One of the following sentences is correct:

a-He invented a pen which can translate the words it writes.

b-He invented which a pen can translate the words it writes. 
c-He invented a pen can which translate the words it writes.

$\mathrm{d}-\mathrm{He}$ invented a pen can translate which the words it writes.

18- Most people buy clothes-----------are classical in style. This is because mostly people are celebrities have access to fashionable clothes before they appear in shops. When you see famous people -clothes follow a certain trend, you know this is the recent trend.

a-who/which/whose

b- which/which/who

c-which/who/ whose

d-which/who/ who

19- Salem is going to participate in the spelling competition,

a-whose actions show that she's always honest with her.

b-who we met in the park are my aunt and cousin.

c-which my school is organizing next month.

d-where Arar, the poet was born.

\section{0- Student: Why do we have to wear school uniform [---]}

Teacher: That [---] s a good question [---] Most schools have rules that tell students how to dress. A uniform helps students to focus on their students and not to worry about what they should wear.
a-[?]/ [ '] [.]
b- [!]/ [ ']/ [?]
c-[?]/ [,]/ [.]
$\mathrm{d}-[?] /[] /,[!]$

21- We went to the place

the treasure was found.

a-where

b-that

c-which

d-whose

22- Help Rashed find out who is the new member of his football team.

a-He is the person who wears a kufiyyeh.

$\mathrm{b}-\mathrm{He}$ is the person who wears a suit.

c-He is the person who wears casual clothes.

$\mathrm{d}-\mathrm{He}$ is the person who wears a red hat.

23- A: Which color is the most exciting among colours? B: for sure

a-Red b-White

c-Green

d-Black

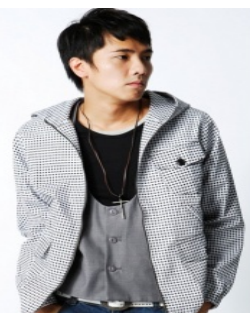

than history.

24- A: Which subject is ---- science or history? B: For me, science is c-the easiest/ most exciting d- easier/ more

a-easy/more exciting

b- more easy/ most exciting exciting

25- The (1) man who (2) is wearing a suit is younger (3) than the man who (4) hair is white.

This sentence includes one mistake:

a-The (1) b-who (2)

c-younger (3)

d-who (4).

\section{Appendix B}

The difficulty factor and the discrimination factor of the test items

\begin{tabular}{|l|l|l|l|l|l|l|l|l|l|l|l|}
\hline $\begin{array}{l}\text { Item } \\
\text { No. }\end{array}$ & $\begin{array}{l}\text { Disc. } \\
\text { Factor }\end{array}$ & $\begin{array}{l}\text { Difficulty } \\
\text { factor }\end{array}$ & $\begin{array}{l}\text { Item } \\
\text { No. }\end{array}$ & $\begin{array}{l}\text { Disc. } \\
\text { Factor }\end{array}$ & $\begin{array}{l}\text { Difficulty } \\
\text { factor }\end{array}$ & $\begin{array}{l}\text { Item } \\
\text { No. }\end{array}$ & Disc. Factor & $\begin{array}{l}\text { Difficulty } \\
\text { factor }\end{array}$ & $\begin{array}{l}\text { Item } \\
\text { No. }\end{array}$ & $\begin{array}{l}\text { Disc. Factor } \\
\text { Difficulty } \\
\text { factor }\end{array}$ \\
\hline 1 & .57 & .67 & 8 & .72 & .28 & 15 & .33 & .71 & 22 & .55 \\
\hline 2 & .30 & .25 & 9 & .29 & .53 & 16 & .40 & .71 & 23 & .63 & .49 \\
\hline 3 & .24 & .45 & 10 & .24 & .45 & 17 & .54 & .68 & 24 & .42 \\
\hline 4 & .44 & .39 & 11 & .52 & .78 & 18 & .49 & .57 & 25 & .72 & .70 \\
\hline 5 & .32 & .52 & 12 & .40 & .75 & 19 & .39 & .62 & & .59 \\
\hline 6 & .29 & .49 & 13 & .63 & .42 & 20 & .70 & .39 & & \\
\hline 7 & .23 & .68 & 14 & .61 & .32 & 21 & .48 & .60 & & \\
\hline
\end{tabular}




\section{Appendix C}

The Answers of the test items

\begin{tabular}{|l|l|l|l|l|l|l|l|}
\hline $\begin{array}{l}\text { Question } \\
\text { No. }\end{array}$ & $\begin{array}{l}\text { Answer } \\
\text { item }\end{array}$ & $\begin{array}{l}\text { Question } \\
\text { No. }\end{array}$ & $\begin{array}{l}\text { Answer } \\
\text { item }\end{array}$ & $\begin{array}{l}\text { Question } \\
\text { No. }\end{array}$ & $\begin{array}{l}\text { Answer } \\
\text { item }\end{array}$ & $\begin{array}{l}\text { Question } \\
\text { No. }\end{array}$ & $\begin{array}{l}\text { Answer } \\
\text { item }\end{array}$ \\
\hline 1 & D & 8 & D & 15 & C & 22 & C \\
\hline 2 & C & 9 & C & 16 & B & 23 & A \\
\hline 3 & C & 10 & A & 17 & A & 24 & D \\
\hline 4 & D & 11 & C & 18 & C & 25 & D \\
\hline 5 & A & 12 & B & 19 & C & & \\
\hline 6 & B & 13 & D & 20 & A & & \\
\hline 7 & C & 14 & D & 21 & A & & \\
\hline
\end{tabular}

\section{Copyrights}

Copyright for this article is retained by the author(s), with first publication rights granted to the journal.

This is an open-access article distributed under the terms and conditions of the Creative Commons Attribution license (http://creativecommons.org/licenses/by/3.0/). 